\title{
Experimental Investigations of Process Parameters INFLUENCE ON DIMENSIONAL ACCURACY AND MECHANICAL Properties OF FDM MANUfaCtUREd PARTS
}

\section{Ahmet Cekic, Derzija Begic-Hajdarevic, Kenan Muhamedagic \& Nermin Guzanovic}
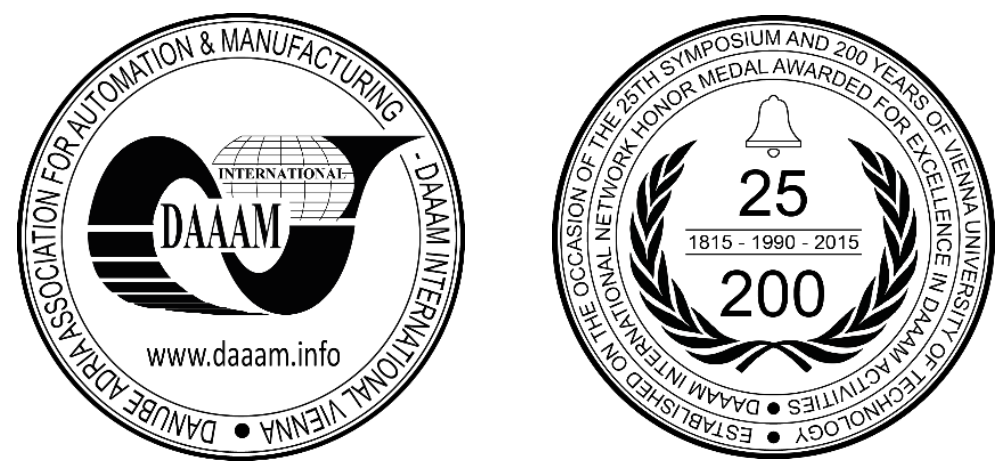

This Publication has to be referred as: Cekic, A[hmet]; Begic-Hajdarevic, D[erzija]; Muhamedagic, K[enan] \& Guzanovic, N[ermin] (2018). Experimental Investigations of Process Parameters Influence on Dimensional Accuracy and Mechanical Properties of FDM Manufactured Parts, Proceedings of the 29th DAAAM International Symposium, pp.0210-0214, B. Katalinic (Ed.), Published by DAAAM International, ISBN 978-3-902734-20-4, ISSN 1726-9679, Vienna, Austria

DOI: $10.2507 / 29$ th.daaam.proceedings.030

\begin{abstract}
For increase of industrial competitiveness and rapid market entry with new products, various additive technologies are increasingly being used today. This paper presents the experimental results of the study the impact of the Fused Deposit Modeling (FDM) process parameters on product quality using different materials. The work is primarily focused on optimizing the important process parameters for the FDM process using the new unexplored material. The making of test samples for dimensional accuracy and mechanical properties tests was carried out on two devices, Flashforge Finder and Ultimaker 3 with two different materials: standard PLA and new composite wood (polymer + wood) material. The obtained results show that new materials that can be produced from wood waste with a certain percentage of adhesives can be used, but before that, process parameters must be precisely defined in order to achieve satisfactory quality of the final products. In this way it has a positive impact on the environment, because wood is a natural and ecologically pure material $\left(\mathrm{CO}_{2}\right.$ neutral).
\end{abstract}

Keywords: additive technologies; fused deposit modelling; fdm process parameters; dimensional accuracy; mechanical properties

\section{Introduction}

The first step in production processes with additive technologies is the creation of 3D CAD models in the appropriate modeling software (Solidworks, Catia V5, Inventor, ...), where dimensions, shape and model constraints are given. Next, the process of cutting the layers model into the suitable software, and adjusting the process parameters on the machine that most often work on the principle of adding "layer-by-layer" material. In the world market, a large number of additive technologies have been implemented, which are primarily distinguished by the method of layer construction (photopolymerization, extrusion and solidification, bonding, laminating, etc.) [4]. One of the more representative additive technologies is the layer-forming technology by extrusion of wire-shaped materials, with controlled melting and subsequent curing of the deposition material (Fused Deposition Modeling - FDM), which is the subject of this paper. 
It is important to note that users have available FDM devices with different technical specifications and configurations. Thus, the general classification of the FDM device is performed on industrial and low-budget desktop devices [8]. Especially low-end FDM devices have experienced a major expansion in the last decade. The difference between certain models of low-budget devices is mainly reflected in the various variants of the relative movement of the extruder head, the number of nozzles, and the dimensions and the possibility of heating the working surface. Although they meet most of the needs of the commercial market, low-budget FDM devices have certain disadventages and limitations. Significant disadvantages compared to industrial devices are reflected in the lower quality of the products, the smaller range of usable materials, dimensional accuracy and tolerances, the smaller working space, and the lower the ability to control the process. Manufacturers of equipment for desktop FDM devices are trying to secure a favorable position in the market with unique and innovative products and the performance of the device [1], [2], [3]. One way to do this is to innovate in terms of materials for making models. In addition to the requirements regarding mechanical, thermal and visual properties, all the more significant stations and material recyclability properties. The development of new materials goes in the direction of biodegradable, ecologically acceptable materials, and today, the most commonly used material from this group is composite materials of polymers and wood.

The main goal of this author's extensive research is to find alternative materials for additive technology. Namely, in order to use the benefits of additive technologies while achieving better quality of manufactured products on certain devices, it is necessary to optimize the process parameters for each building material [5], [6], [7].

\section{Experimental research}

As representative of the quality of products manufactured with FDM technology, we have analyzed deviations from the design shape and dimension of the model, the presence of surface defects that can be visually detected and the tensile test. 3D modeling models are modeled in Solidworks 2013 software, and the Stl. print format preparation is done in FlashPrint (Frashforge Finder) and Ultimaker Cura (Ultimaker 3). For comparison of FDM material, the analysed models were made with standard PLA (PolyLactic Acid) and new non-standard Wood material. Wood material for experimental research was obtained by mixing PLA and 35\% wood. The influence of the FDM parameter parameters (temperature and printing speed, layer thickness, density and fill form, model orientation, ...) on the quality of the product was analyzed.

\subsection{The influence of the printing temperature on the dimensional accuracy on the final product}

To test the influence of printing temperature on dimension accuracy, 12 models - test tube (Figure 1a) and 6 of PLA and 6 of Wood material were made. Test tubes were made on the FDM Flashforge Finder. The temperature ranged from $190{ }^{\circ} \mathrm{C}$ to $240{ }^{\circ} \mathrm{C}$ with a step of $10{ }^{\circ} \mathrm{C}$. The other parameters have been optimized and are kept constant during the production of all tubes. The appearance of finished test tubes of PLA and Wood material is shown in Figures $1 \mathrm{~b}$ and $1 \mathrm{c}$. Measurement of dimensions and shapes was performed on a universal two-coordinate measuring microscope ZKM 01 $250 \mathrm{C}$.

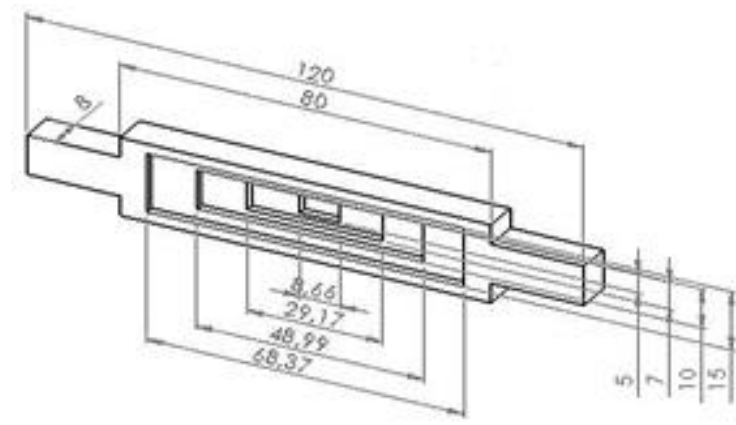

a)

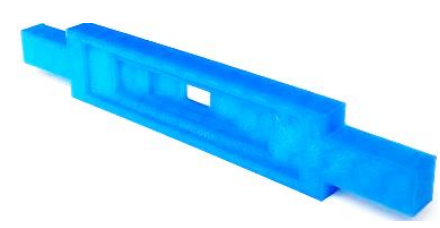

b)

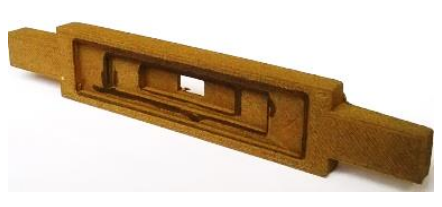

c)

Fig. 1. a) Model of test tubes obtained in Solidworks 2013; b) The appearance of the printed tube - PLA material; c) The appearance of the printed tube - Wood material

Analyzing the dimension deviations of the tubes made of Wood material in the temperature range from $190{ }^{\circ} \mathrm{C}$ to 240 ${ }^{\circ} \mathrm{C}$, the trend of increasing the external dimensions from $0.15 \mathrm{~mm}$ to $0.76 \mathrm{~mm}$ and the reduction of the interior dimensions from $0.10 \mathrm{~mm}$ to $0.57 \mathrm{~mm}$ was observed. For better visibility, Figure 2 shows diagrams of deviations of the measures from the required values for two external and two internal measures. The deviations are more pronounced with the increase in the printing temperature.

The measurement of the dimensions on the test tubes made from the PLA material can not detect the legality of the change of the deviations. Namely, using standard material for modeling but with recommended parameters of the material manufacturer, smaller deviations shapes and dimensions are obtained. This confirms the importance of optimizing process parameters when using new unexplored materials. 


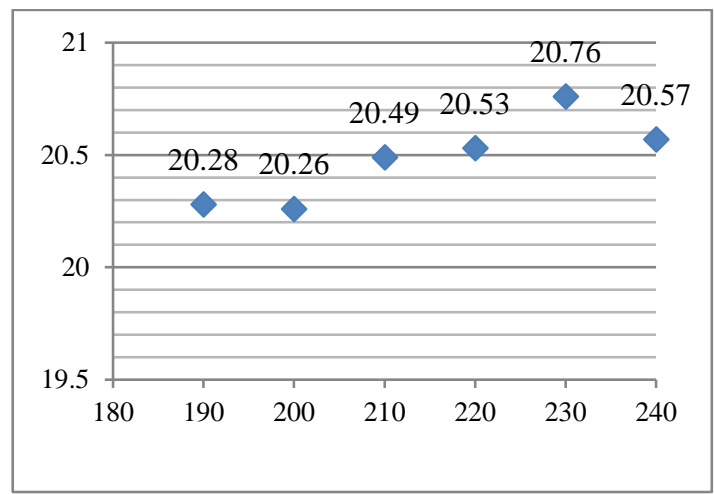

a)

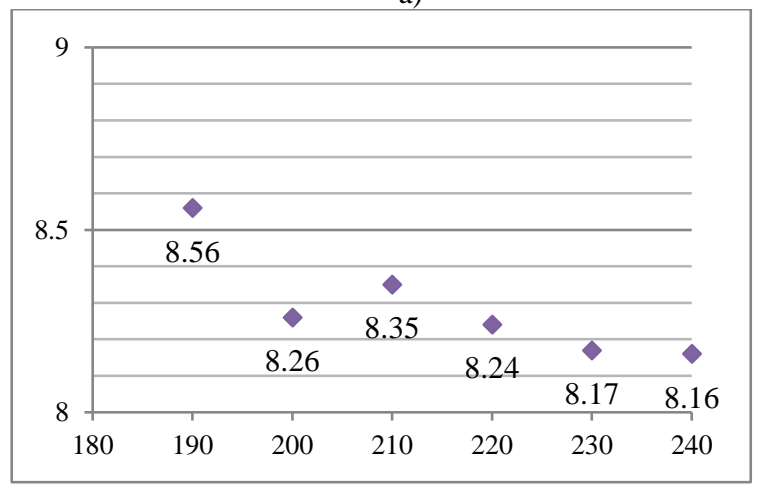

c)

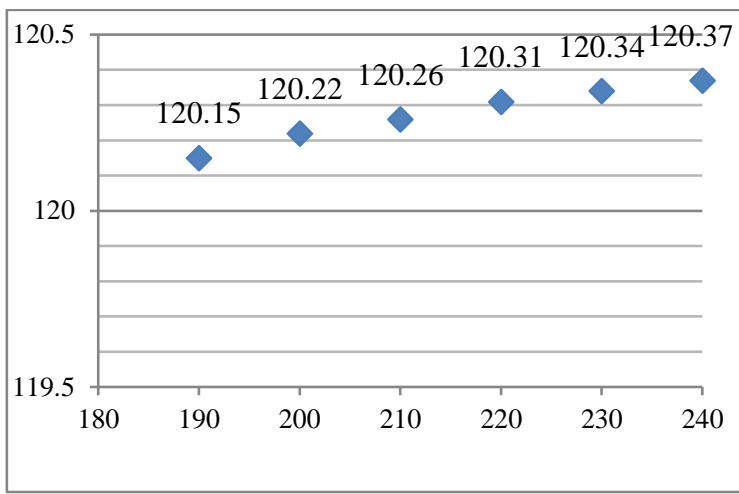

b)

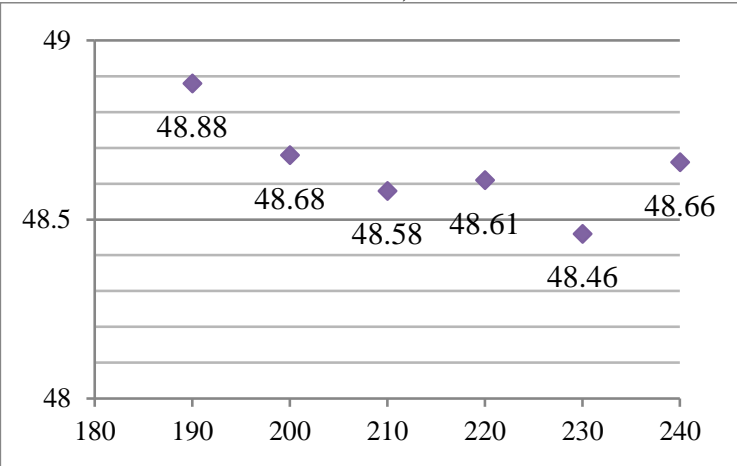

d)

Fig. 2. Measured values in relation to required values; a) 20,00 mm; b) $120,00 \mathrm{~mm}$; c) $8,66 \mathrm{~mm}$; d) $48,99 \mathrm{~mm}$

\subsection{The influence of shape and fill percentage on the quality of Wod material}

To measure the effect of shape and percentage of fill (density) on dimensional accuracy, models were made in cubic shape of 15x15x15 mm. The models are made of three different materials: standard PLA, Laywoo - D3 (manufacturer LAY Filaments) [1] and Wood material. By analyzing the productivity, mechanical properties and product quality, previous experimental studies have found that the optimal form of filling is hexagonal and the printing temperature of $220^{\circ} \mathrm{C}$. Figure 3 shows the maximum deviations of the dimensions for the models made of three different materials at a different percentage of filling. It can be concluded that the Wood material analyzed in this paper has a better dimensional stability than the PLA material for filling values of $50 \%$ to $100 \%$ and worse than the composite LayWoo D - 3 material. Also, in Wood materials, a small fill percentage (5\% and $25 \%$ ) causes cracks, especially on the upper surface because there is not enough material inside.

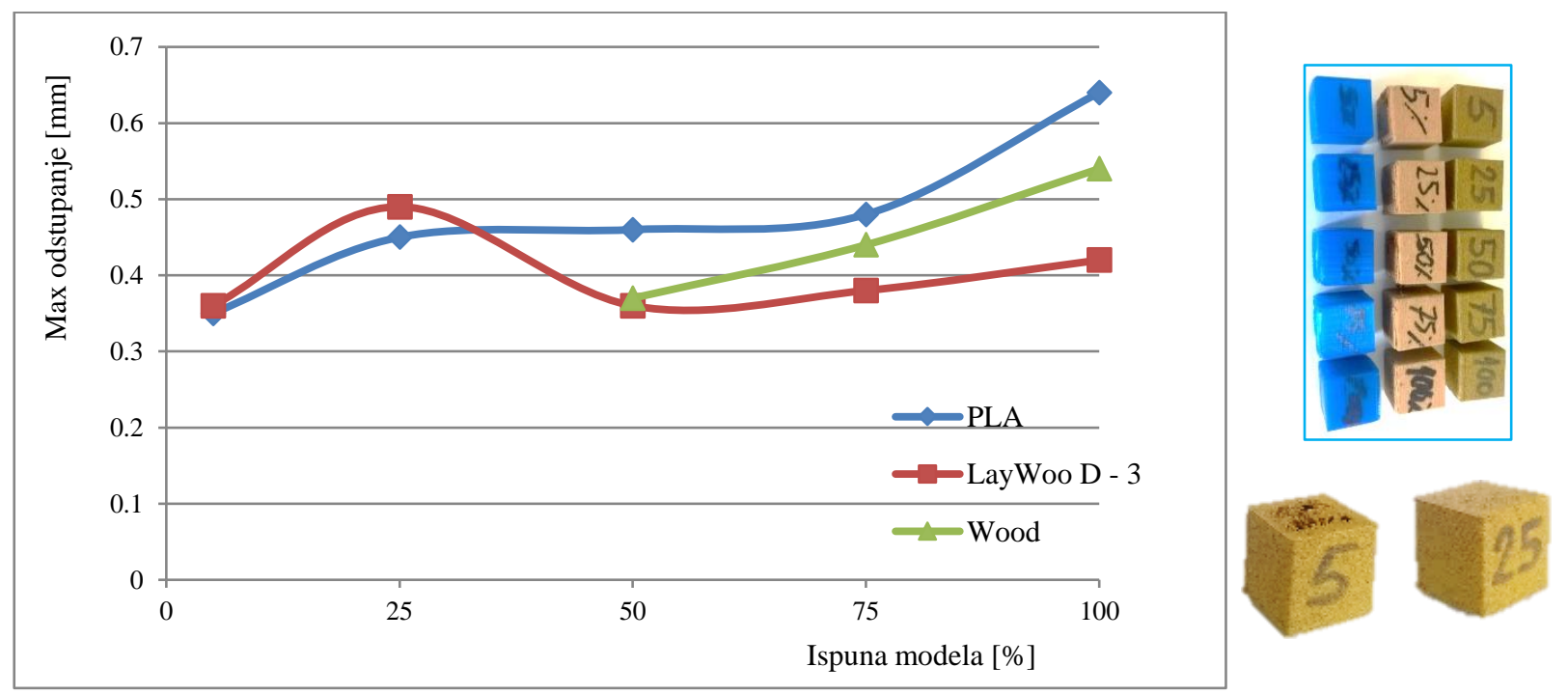

Fig. 3. Comparison of maximum deviations of the model dimension by varying the percentage of filling 


\subsection{Tensile test of Wood material}

A higher number of test tubes according to ISO / TC 61 DR has been made for tensile testing. The constant parameters of the process were: $100 \%$ fill percentage, fill form - hexagonal, print speed $60 \mathrm{~mm} / \mathrm{s}$ at $220{ }^{\circ} \mathrm{C}$ printing temperature. The shape of the tubes and dimensions are shown in Figure 4.
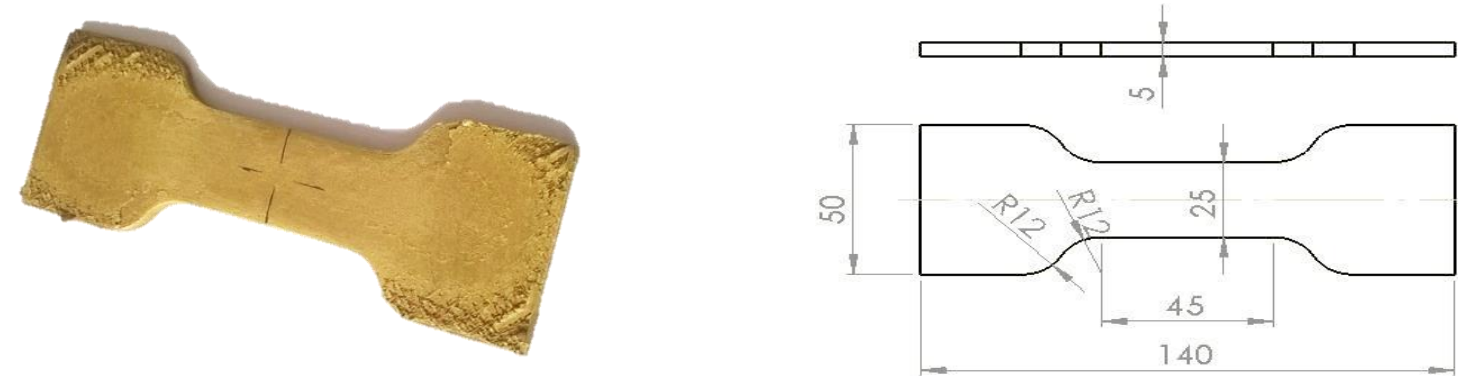

Fig. 4. Appearance and dimensions of test tube for tensile testing

For tensile testing of Wood material, the Zwick 1435 digital testing machine was used with a measuring range from 0 to $5 \mathrm{kN}$. Machine resolution is $0.1 \mathrm{~N}$ for force and $0.01 \mathrm{~mm}$ for elongation. For better visibility, Figure 5 shows the Hook diagram F - $\Delta \mathrm{l}$ for the two test tubes of Wood material. The conclusion is that the Wood material, in the initial phase of the tensile test, is subjected to a rapid change in shape for a small increase in force, and then the structure of the material stabilizes, the diagram shows a nearly linear force - elongation direction. The average tensile strength of the test tubes of Wood was calculated and was $15.20 \mathrm{MPa}$ with an average elongation of $4.06 \%$. Analyzing the fracture surfaces, it was found that a brittle fracture occurred during the test of the test tube.
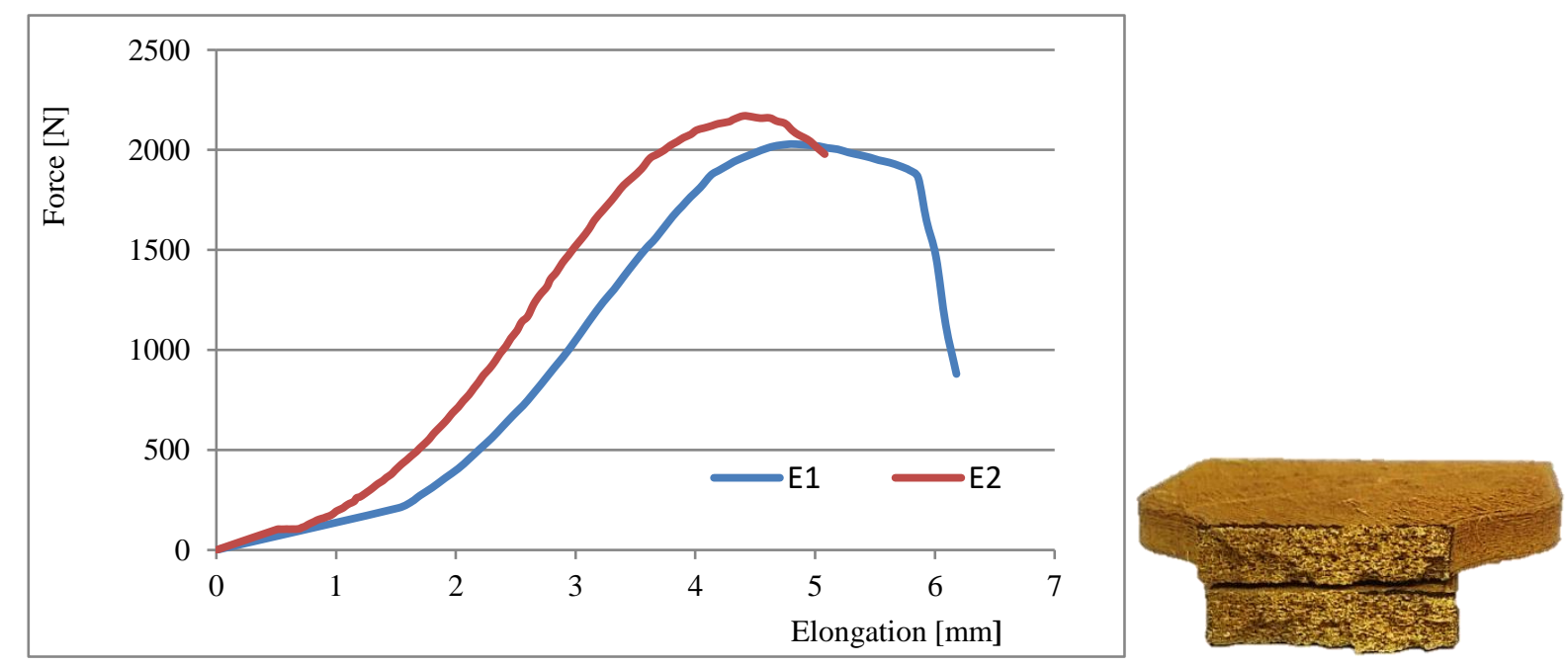

Fig. 5. Hook Diagram F - $\Delta \mathrm{l}$ for two test tubes of Wood material and the appearance of the fracture surface

Given that Wood material belongs to the class of low strength material and due to imprecision of the machine for low strenght materials, HBM type 6/ 120LY11 measuring strips used for testing steel structures have also been used for more precise measurement of elongation and deformation of the test tubes. Some of the characteristics of the measuring strips are: specific resistance of $120 \Omega \pm 0,35 \%, \mathrm{~K}$ - factor 2,02 $\pm 1 \%$, temperature factor $90 \mathrm{ppm} / \mathrm{K}$ and coefficientt of linear thermal expansion $\alpha=11 \mathrm{ppm} / \mathrm{K}$. Since the tested material had significantly different properties from steel, two measuring strips were used during the test: one active and one compensating. The active and compensating strip are connected to the Wheatstone Bridge. In addition to being interconnected, the measuring strips are connected with one wire for the DMC 9012 measuring amplifier. The fact that one scan performs a 30540 point reading of the deformation velocity data indicates that this is an extremely accurate test. The HBM Catman program was used to acquire and monitor the measurement results.

During tensile testing with the measuring strips, the same speed of movement of the upper jaw (minimum) was used as in the classical test, time and force are proportional in both cases. Therefore, the measurement results are shown in the function of time - deformation in the test interval of min. $0 \mathrm{~N}$ to $\max .1250 \mathrm{~N}$. Considering that with the aid of the measuring strips the slip effect was eliminated, and that identical diagrams were obtained for test tubes, Figure 6 shows diagram for only one test tube with the force values in $[\mathrm{N}]$ at the characteristic points. 


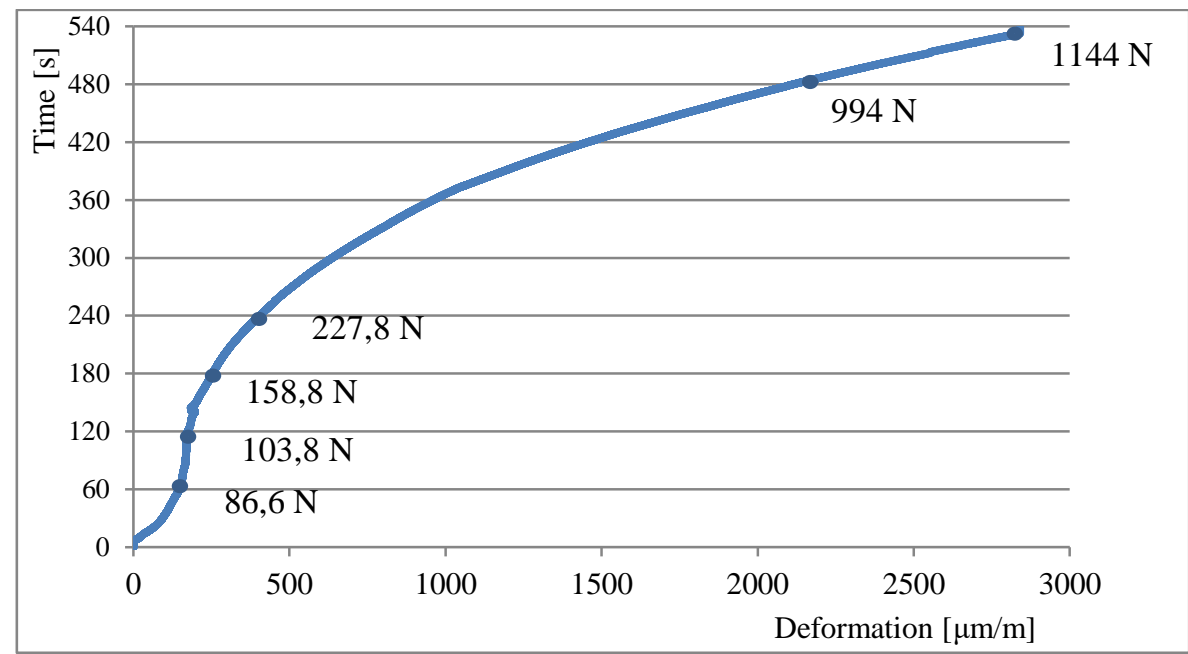

Fig. 6. Diagram of deformation - time during testing with measuring strips

\section{Conclusion}

Although the areas of application of FDM technology are constantly widening, problems of quality control, standardization and accreditation are still not completely resolved, so unfortunately their serious expansion is still limited. Also, for the more significant application of additive technologies in the industry, serious researches is needed to find new materials for the quick production of functional products.

This paper presents the effects of FDM process parameters on product quality. It has been shown that by optimizing the influential process parameters for the corresponding building material, minimal deviations of the dimensions and shape of the finished product as well as better product quality can be obtained. Experimental research has shown that the composite Wood material has very low expressed warping and good adhesion to the substrate. It is very brittle (as a filament) but after printing it is much more flexible. After printing the products are soft, but after 24 hours they become more stiff. The behavior of Wood material (shrinking and warping) during the change of temperature, as well as percentage and form filling was determined. An optimal print temperature of $200{ }^{\circ} \mathrm{C}$ to $210{ }^{\circ} \mathrm{C}$ is determined, a percentage of fill from $75 \%$ to $100 \%$ with a hexagonal fill pattern. Additionally, in order to improve the quality of the product, the recommendations are: use print rafts, heating chambers (a better quality device), and make sure to optimize the print speed as well as increase the diameter of the nozzle $(\mathrm{min} .0 .6 \mathrm{~mm})$, etc.

The authors of this paper plan to continue experimental research in order to find new alternative materials using modern devices, with special emphasis on research and optimization of process parameters, especially for industrial FDM devices as well as for other additive technologies.

\section{References}

[1] Cekic, A.; Obucina, M.; Begic-Hajdarevic, D. \& Hebibovic, M. (2017). Analysis of Mechanical Properties of Alternative Materials for Process Deposit Modeling, Proceedings of the 28th DAAAM International Symposium, ISBN 978-3-902734-11-2, ISSN 1726-9679, Katalinic, B. (Ed.), pp. 0253-0257, Published by DAAAM International, Vienna, City, DOI:10.2507/28th.daaam.proceedings.034

[2] Valerga, A. P.; Batista, M.; Fernandez-Vidal, S. R.; Gomez-Parra, A. \& Barcena, M. (2016). Preliminary Study of the Influence of Manufacturing Parameters in Fused Deposition Modeling, Proceedings of the 26th DAAAM International Symposium, ISBN 978-3-902734-07-5, ISSN 1726-9679B. Katalinic, B. (Ed.), pp.1004-1008, Published by DAAAM International, Vienna, DOI: 10.2507/26th.daaam.proceedings.141

[3] Cekic, A.; Rasovic, N.; Obad, M.; Kaljun, J.; Dolsak, B. \& Begic-Hajdarevic, D. (2016). Production of optimized layered products using intelligent support, Proceedings of the 26th DAAAM International Symposium, ISBN 9783-902734-07-5, ISSN 1726-9679, Katalinic, B. (Ed.), pp. 0271-0279, Published by DAAAM International, Vienna, City, DOI:10.2507/26th.daaam.proceedings.037

[4] Godec, D. \& Šercer M. Aditivna proizvodnja, ISBN 978-953-7738-26-6, Zagreb, 2015.

[5] Godec, D.; Radoš I. \& Šercer M. Performance comparison of low- budget 3D printers, University of Zagreb, Faculty of Mechanical Engineering and Noval Arctitecture, Zagreb, 2016.

[6] Dudek, P. \& Rapacz- Kmita A. Rapid prototyping: Technologies, Materials and advances, Arch. Metall. Mater., Vol.61, 2016.

[7] Boschetto, A. \& Bottini, L. (2015) Triangular mesh offset aiming to enhance Fused Deposition Modeling accuracy, International Journal of Advanced Manufacturing Technology, 80 (99 - 111)

[8] https://wohlersassociates.com. 